\title{
Reactivity of imidazolidin-4-one derivatives of primaquine: implications for prodrug design
}

\author{
Paula Chambel, ${ }^{\mathrm{a}, \mathrm{b}}$ Rita Capela, ${ }^{\mathrm{a}}$ Francisca Lopes, ${ }^{\mathrm{a}}$ Jim Iley, ${ }^{\mathrm{c}}$ José Morais, \\ Luís Gouveia, ${ }^{\mathrm{b}}$ José R. B. Gomes, ${ }^{\mathrm{d}}$ Paula Gomes ${ }^{\mathrm{d}}$ and Rui Moreira ${ }^{\mathrm{a}, *}$ \\ ${ }^{a}$ Centro de Estudos de Ciências Farmacêuticas, Faculdade de Farmácia da Universidade de Lisboa, Av. Forças Armadas, \\ P-1649-019 Lisboa, Portugal \\ ${ }^{\mathrm{b}}$ UCTM, Faculdade de Farmácia da Universidade de Lisboa, Av. Forças Armadas, P-1649-019 Lisboa, Portugal \\ ${ }^{\mathrm{c}}$ Department of Chemistry, The Open University, Milton Keynes, MK7 6AA, United Kingdom \\ ${ }^{\mathrm{d}}$ Centro de Investigação em Química da Universidade do Porto, Departamento de Química da Faculdade de Ciências do Porto, \\ Rua do Campo Alegre 687, P-4169-007 Porto, Portugal
}

Received 13 June 2006; revised 3 August 2006; accepted 7 August 2006

Available online 24 August 2006

\begin{abstract}
In contrast to peptide-based imidazolidin-4-ones, those synthesized from $N$ - $(\alpha$-aminoacyl) derivatives of the antimalarial drug, primaquine and ketones are unexpectedly stable in $\mathrm{pH} 7.4$ at $37^{\circ} \mathrm{C}$. The kinetics of hydrolysis of primaquine-based imidazolidin-4-ones were investigated in the $\mathrm{pH}$ range $0.3-13.5$ at $60^{\circ} \mathrm{C}$. The hydrolysis to the parent $\alpha$-aminoacylprimaquine is characterized by sigmoidalshaped $\mathrm{pH}$-rate profiles, reflecting the spontaneous decomposition of both unionized and protonated (at N-1) forms of the imidazolidin-4one. The kinetically determined $\mathrm{p} K_{\mathrm{a}}$ values are ca. 3.6-4.0, i.e., $4 \mathrm{p} K_{\mathrm{a}}$ units lower than those of amino acid amides, thus implying that hydrolysis of imidazolidin-4-ones at $\mathrm{pH} 7.4$ involves the unionized form. Reactivity of this form decreases with the steric crowding of the amino acid $\alpha$-substituent. In contrast, the rate constant for the spontaneous decomposition of the unionized form increases sharply for imidazolidin-4-ones derived from cyclic ketones, an observation that can be explained by the $I$-strain (internal strain) effect. These results are consistent with a mechanism of hydrolysis involving an $\mathrm{S}_{\mathrm{N}}$ 1-type unimolecular cleavage of the imidazolidin-4-one C2-N3 bond with departure of an amide-leaving group. The mechanism for the decomposition of the protonated imidazolidin-4-one is likely to involve an amide-carbonyl oxygen protonated species, followed by the $\mathrm{C} 2-\mathrm{N} 3$ bond scission, as supported by computational studies. The results herein presented suggest that imidazolidin-4-ones derived from simple $N$-alkyl $\alpha$-aminoamides are too stable and therefore, may be useful as slow drug release prodrugs.
\end{abstract}

(c) 2006 Elsevier Ltd. All rights reserved.

\section{Introduction}

Compounds containing an $\alpha$-aminoamide moiety, such as peptides with a free N-terminal amino group, react with aldehydes and ketones to yield imidazolidin-4-ones, $\mathbf{1}$, as depicted in Scheme 1. ${ }^{1-4}$ In aqueous solutions, compounds $\mathbf{1}$ revert back to the parent $\alpha$-aminoamide (peptide) and aldehyde or ketone at a rate that is dependent on $\mathrm{pH}$, on the structure of the $\alpha$-aminoamide substituents $\left(\mathrm{R}^{1}\right.$ and $\left.\mathrm{R}^{4}\right)$, and on the structure of the carbonyl component $\left(\mathrm{R}^{2}\right.$ and $\left.\mathrm{R}^{3}\right){ }^{4,5}$ In contrast to peptides, the hydrolysis of imidazolidin-4-ones $\mathbf{1}$ is not subjected to enzyme catalysis and thus imidazolidin-4-ones have been suggested as potentially useful prodrugs to protect the N-terminal amino acid residue of peptides against aminopeptidase-catalyzed hydrolysis. ${ }^{6-8}$

Keywords: Imidazolidin-4-ones; Prodrugs; Primaquine; Kinetics; Substituent effects; Mechanism of hydrolysis.

* Corresponding author. Tel.: +351 217946477; fax: +351 217946470; e-mail: rmoreira@ff.ul.pt
Peptide imidazolidin-4-one derivatives, $\mathbf{1}$, are readily hydrolyzed to the parent peptide in $\mathrm{pH} 7.4$ buffer at $37^{\circ} \mathrm{C}$, usually with half lives ranging from 1 to $30 \mathrm{~h}$ (Scheme 1$).^{5-8}$ When compared with the parent peptides several imidazolidin-4one prodrugs of Met-enkephalin and Leu-enkephalin, e.g., $\mathbf{2}$, display improved stability in human plasma, rabbit liver homogenate, and toward aminopeptidase. ${ }^{7}$ This prodrug strategy has been extended to improve the bioavailability of ampicillin, a $\beta$-lactam antibiotic that also contains a $\alpha$-aminoamide backbone; ${ }^{2,4}$ the corresponding imidazolidin4-one, hetacillin (3), is rapidly hydrolyzed to ampicillin in

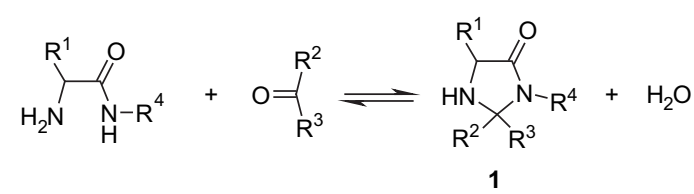

Scheme 1. 
aqueous solutions ${ }^{4}$ and in vivo. ${ }^{9}$ More recently, the imidazolidin-4-one approach has been proposed to develop oil-injectable depots for the $\alpha$-aminoanilide anesthetic agent prilocaine. $^{10}$

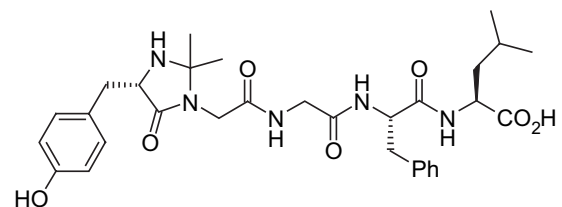

2

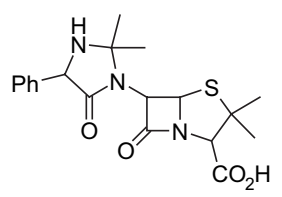

3 differences in reactivity, as previous authors had suggested that substituents at the N-3 nitrogen atom in dipeptide and tripeptide imidazolidin-4-ones exert a small effect on hydrolysis rates. ${ }^{7}$ Obviously, understanding the reason for such large differences in reactivity is fundamental to being able to extend the imidazolidin-4-one prodrug approach to $\alpha$ aminoamides other than peptides. In this context, we now present a kinetic study of hydrolysis of imidazolidin-4ones 4 undertaken to elucidate the structural factors that affect their reactivity and to assess the usefulness of this prodrug type to other $\alpha$-aminoamide drug moieties.

\section{Results and discussion}

potential pro-prodrugs of the antimalarial primaquine, 5 (PQ). ${ }^{11,12}$ Compounds 4 were designed with the aim of reducing the metabolic inactivation pathway of primaquine that involves oxidative deamination at the primary amino group, ${ }^{13-16}$ as well as to reduce the blood toxicity induced by primaquine, particularly its ability to induce oxidation of oxyhemoglobin to methemoglobin. ${ }^{17}$ The proposed activation pathway of imidazolin-4-ones 4 implies the spontaneous hydrolysis to the corresponding amino acid derivatives 6, which in turn can be enzymatically hydrolyzed to the parent drug by parasitic aminopeptidases. In order to circumvent hydrolysis by the GI tract peptidases, the imidazolidin-4-one pro-prodrug should hydrolyze at a rate that allows quantitative formation of $\mathbf{6}$ after oral absorption. Quite surprisingly, our initial studies showed that primaquine derived imidazolidin-4-ones $\mathbf{4}$ are reasonably stable compounds, hydrolyzing to the corresponding amino acid derivatives, 6, in $\mathrm{pH} 7.4$ buffer at $37{ }^{\circ} \mathrm{C}$ with half lives ranging from 9 to 30 days, ${ }^{11,12}$ i.e., $50-100$ times slower than most of the imidazolidin-4-one counterparts derived from di- and higher peptides. We were surprised by these large
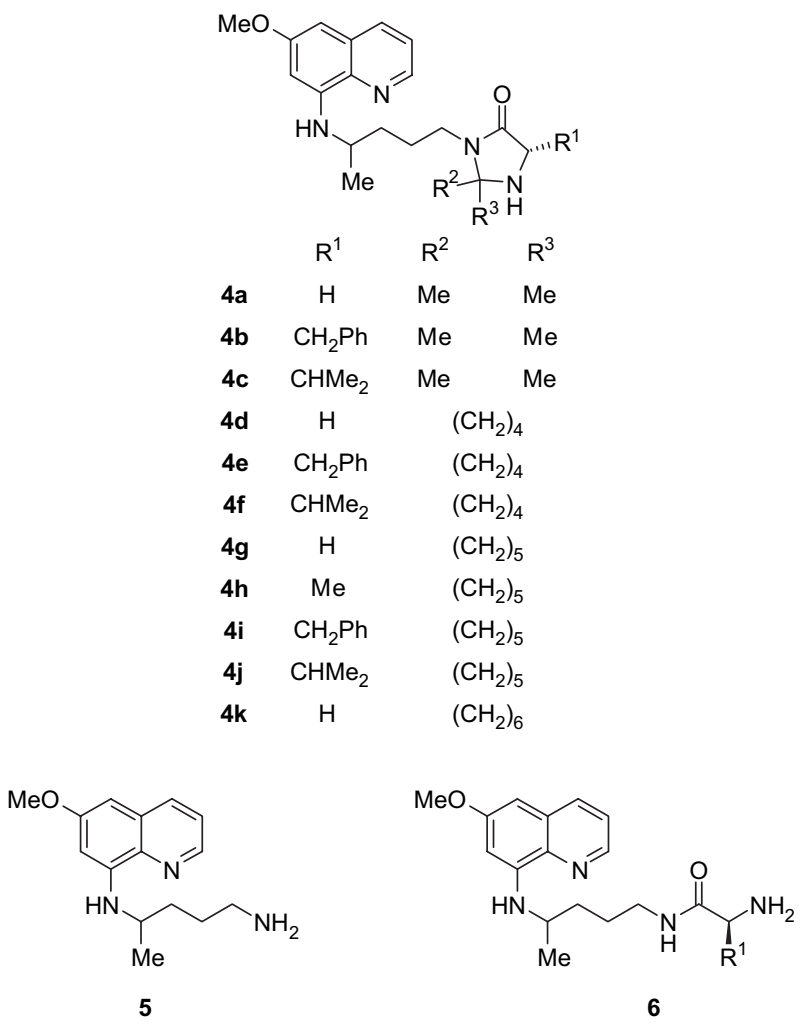

\subsection{Kinetics and products of hydrolysis}

As revealed by HPLC analysis, all compounds $\mathbf{4}$ hydrolyze quantitatively at $60{ }^{\circ} \mathrm{C}$ to the corresponding amino acid derivative 6 with first-order kinetics up to 4 half lives, over the $\mathrm{pH}$ range $0.5-12$. For the imidazolidin-4-one $\mathbf{4 b}$ it was also possible to observe the hydrolysis of the corresponding amino acid derivative 6 to primaquine at $\mathrm{pH}>10$. An example of product analysis is presented in Figure 1A for the hydrolysis of compound $\mathbf{4 b}$ in $\mathrm{pH}$ 13.7, where the solid lines represent the best computer fit to the experimental data of the consecutive first-order reactions model (i.e., $\mathbf{4} \rightarrow \mathbf{6} \rightarrow \mathbf{5}$ ) represented by Eqs. 1-3. ${ }^{18}$

$[4]=[4]_{0} \mathrm{e}^{-k_{1} t}$

$[6]=\frac{[4]_{0} k_{1}}{k_{2}-k_{1}}\left(\mathrm{e}^{-k_{1} t}-\mathrm{e}^{-k_{2} t}\right)$

$[5]=\frac{[4]_{0}}{k_{2}-k_{1}}\left[k_{2}\left(1-\mathrm{e}^{-k_{1} t}\right)-k_{1}\left(1-\mathrm{e}^{-k_{2} t}\right)\right]$

Here $[\mathbf{4}]_{0}$ is the concentration of the imidazolidin-4-one at time zero, and $k_{1}$ and $k_{2}$ are the pseudo-first-order rate constants for the hydrolysis of the starting material $\mathbf{4}$ and amino acid derivative 6, respectively (data not shown). For $6 \mathbf{b}$ (primaquine-Phe), values of $k_{2}$ so-obtained can be plotted versus $\left[\mathrm{OH}^{-}\right]$to obtain a value of $k_{\mathrm{OH}^{-}}=3.6 \times 10^{-2} \mathrm{M}^{-1} \mathrm{~h}^{-1}$; this compares favorably with the value of $k_{\mathrm{OH}^{-}}=2.2 \times$ $10^{-2} \mathrm{M}^{-1} \mathrm{~h}^{-1}$ determined independently for the hydrolysis of $\mathbf{6 b}$ in the same $\mathrm{pH}$ range ( $\mathrm{pH} 11-13.7)$.

At $\mathrm{pH}$ values between 2 and 11 no formation of primaquine was observed over the time-scale for the complete hydrolysis of $\mathbf{4 b}$. However, formation of primaquine was observed in the hydrolysis of $\mathbf{4 b}$ at $\mathrm{pH}<2$. The species profile for the hydrolysis at low $\mathrm{pH}$ values also fits the model for two consecutive first-order reactions (Fig. 1B). From the derived plot of $k_{2}$ versus $\left[\mathrm{H}^{+}\right]$, a value for $k_{\mathrm{H}^{+}}$of $1.5 \times 10^{-1} \mathrm{M}^{-1} \mathrm{~h}^{-1}$ was determined for the acid-catalyzed hydrolysis of $\mathbf{6 b}$ to primaquine, which compares favorably with the value of $2.0 \times 10^{-1}$ $\mathrm{M}^{-1} \mathrm{~h}^{-1}$ determined independently for the hydrolysis of $\mathbf{6 b}$ over the same $\mathrm{pH}$ range ( $\mathrm{pH}$ 0.3-2.0). The higher efficiency of the acid-catalyzed hydrolysis of $\mathbf{6 b}$ when compared with the alkaline hydrolysis can be ascribed to the stronger 

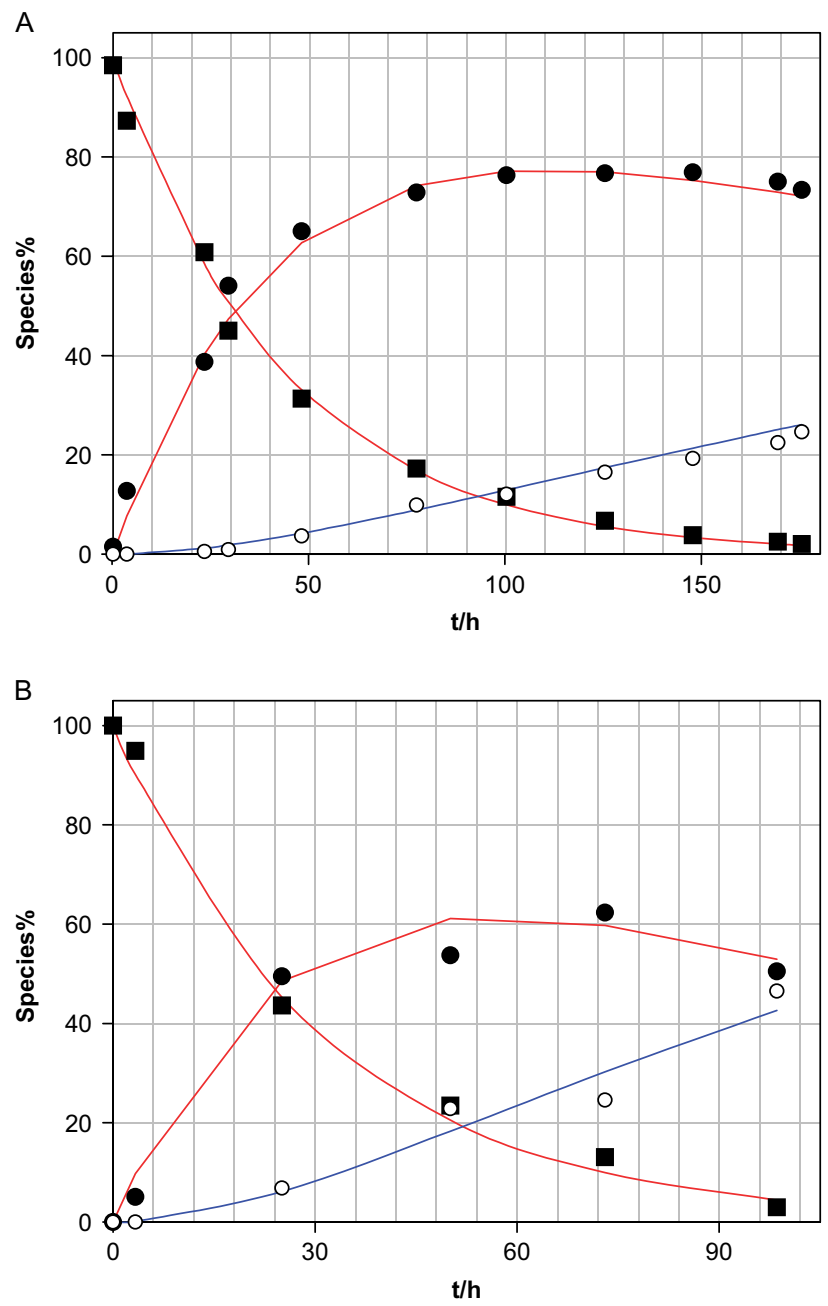

Figure 1. Time profile for the hydrolysis at $60^{\circ} \mathrm{C}$ of $\mathbf{4 b}(\boldsymbol{\square})$ into PhePQ (-) and PQ (O) in (A) $0.1 \mathrm{M} \mathrm{NaOH}$ and (B) $0.5 \mathrm{M} \mathrm{HCl}$ solutions.

electron-withdrawing ability of the protonated amino group $\left(\mathrm{p} K_{\mathrm{a}} \text { ca. 8.0 }\right)^{19}$ over the corresponding neutral form $\left(\sigma^{*} \mathrm{NH}_{3}^{+}=3.76 ; \sigma^{*} \mathrm{NH}_{2}=0.62\right)^{20}$ that increases the reactivity of the amide-carbonyl carbon atom toward nucleophiles.

The rates of hydrolyses of imidazolidin-4-ones $\mathbf{4}$ at a fixed $\mathrm{pH}$ value were found to be independent of buffer concentration over a 10-fold buffer concentration range, indicating the absence of general acid or base catalysis (Table 1). The influence of $\mathrm{pH}$ on the rate of hydrolysis of compounds 4 is shown in Figure 2, where the logarithm of the observed pseudo-first-order rate constant, $k_{1}$, is plotted against $\mathrm{pH}$.

Table 1. First-order rate constants for the hydrolysis of $\mathbf{4 b}$ in acetate and phosphate buffers at $60{ }^{\circ} \mathrm{C}$, with ionic strength maintained at $0.5 \mathrm{~mol} \mathrm{dm}^{-3}$ by addition of $\mathrm{NaClO}_{4}$

\begin{tabular}{llll}
\hline Buffer & {$[$ Buffer $] / \mathrm{mol} \mathrm{dm}^{-3}$} & $\mathrm{pH}$ & $10^{2} k_{\text {obs }} / \mathrm{h}^{-1}$ \\
\hline $\mathrm{CH}_{3} \mathrm{CO}_{2} \mathrm{H}$ & 0.005 & 3.99 & 2.01 \\
& 0.01 & 3.99 & 1.53 \\
& 0.05 & 3.98 & 1.66 \\
$\mathrm{H}_{2} \mathrm{PO}_{4}^{-}$ & 0.002 & 6.01 & 1.75 \\
& 0.005 & 6.05 & 1.65 \\
& 0.01 & 5.95 & 1.72 \\
\hline
\end{tabular}

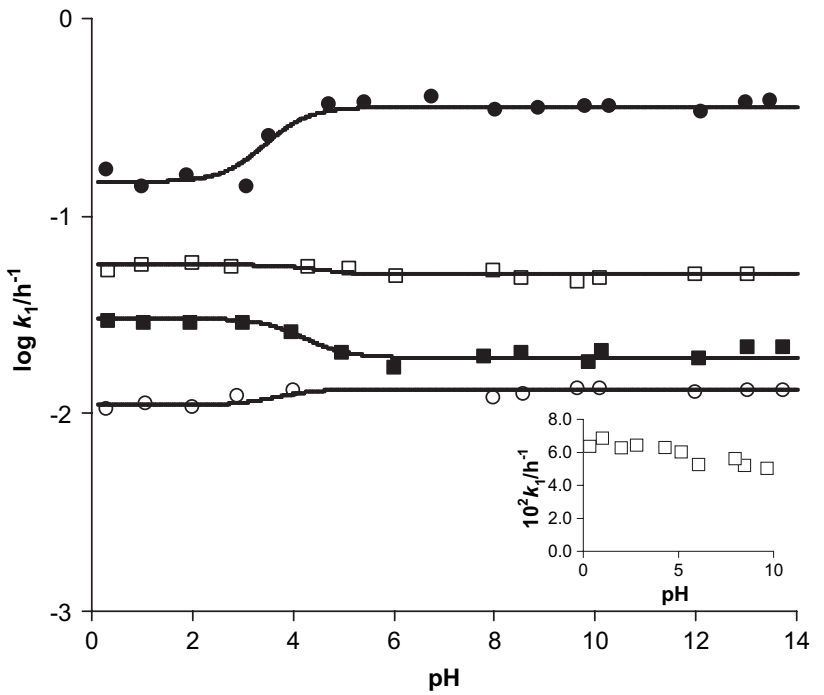

Figure 2. The $\mathrm{pH}$-rate profiles for the hydrolysis of the imidazolidin-4-ones 4b $(\square), 4 c(\bigcirc), 4 d(\bigcirc)$, and $4 \mathbf{e}(\square)$ in aqueous solutions at $60^{\circ} \mathrm{C}$; the insert is a plot of $k_{1}$ versus $\mathrm{pH}$ for $\mathbf{4 e}$.

All $\mathrm{pH}-$ rate profiles have a sigmoid shape, with two $\mathrm{pH}$-independent regions. Such sigmoid $\mathrm{pH}$-rate profiles have been reported for other imidazolidin-4-ones ${ }^{4,5}$ as well as for their acyclic counterparts, $N$-Mannich bases, ${ }^{21}$ and can be accounted for by assuming that both the protonated, $\mathrm{SH}^{+}$, and the unionized, S, forms of the substrate undergo spontaneous hydrolysis (Scheme 2). The best computer fit (solid line) to the experimental data for $\mathbf{4}$ in Figure 2 was achieved using Eq. 4:

$k_{1}=k_{\text {neut }} \frac{K_{\mathrm{a}}}{K_{\mathrm{a}}+\left[\mathrm{H}^{+}\right]}+k_{\text {prot }} \frac{\left[\mathrm{H}^{+}\right]}{K_{\mathrm{a}}+\left[\mathrm{H}^{+}\right]}$

where $k_{\text {neut }}$ and $k_{\text {prot }}$ are the apparent first-order rate constants for the decomposition of neutral and protonated forms of $\mathbf{4}, K_{\mathrm{a}}$ is the acid dissociation constant of the protonated $\mathbf{4}$, and $\left[\mathrm{H}^{+}\right] /\left(K_{\mathrm{a}}+\left[\mathrm{H}^{+}\right]\right)$and $K_{\mathrm{a}} /\left(K_{\mathrm{a}}+\left[\mathrm{H}^{+}\right]\right)$represent, respectively, the fractions of the protonated and neutral forms of 4 present in solution. The $k_{\text {neut }}$ and $k_{\text {prot }}$ values derived either from the $\mathrm{pH}$-rate profiles or determined at $\mathrm{pH} 11$ (for $k_{\text {neut }}$ ) and $\mathrm{pH} 0.3$ (for $k_{\text {prot }}$ ) are presented in Table 2. Also included in Table 2 are the $\mathrm{p} K_{\mathrm{a}}$ values for compounds $\mathbf{4}$, derived from the $\mathrm{pH}$-rate profiles. The good agreement between the

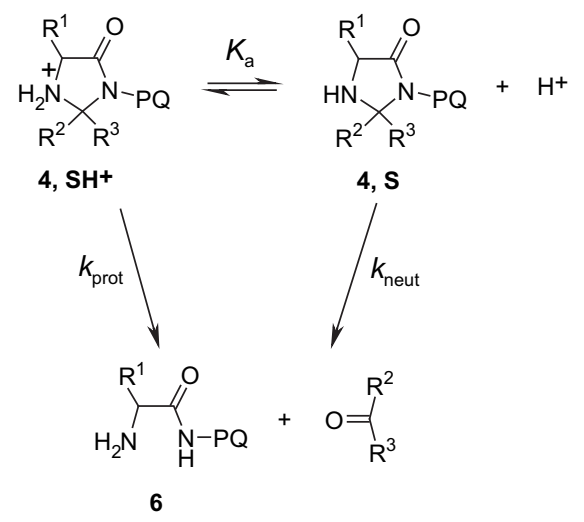

Scheme 2. 
Table 2. First-order rate constants for the hydrolysis of the neutral, $k_{\text {neut }}$, and protonated, $k_{\text {prot }}$, forms of the imidazolidin-4-ones 4 , determined at $60{ }^{\circ} \mathrm{C}$, with ionic strength maintained at $0.5 \mathrm{~mol} \mathrm{dm}^{-3}$ with addition of $\mathrm{NaClO}_{4}$, also included are the $\mathrm{p} K_{\mathrm{a}}$ values determined from the $\mathrm{pH}$-rate profile

\begin{tabular}{llll}
\hline Compound & $10^{2} k_{\text {neut }} / \mathrm{h}^{-1}$ & $10^{2} k_{\text {prot }} / \mathrm{h}^{-1}$ & $\mathrm{p} K_{\mathrm{a}}$ \\
\hline $\mathbf{4 a}$ & 1.80 & $\mathrm{nd}$ & $\mathrm{nd}$ \\
$\mathbf{4 b}$ & 1.90 & 3.05 & 3.95 \\
$\mathbf{4 c}$ & 1.32 & 1.09 & 3.70 \\
$\mathbf{4 d}$ & 35.2 & 14.7 & 3.61 \\
$\mathbf{4 e}$ & 5.02 & 5.61 & 3.98 \\
$\mathbf{4 f}$ & 4.61 & $\mathrm{nd}$ & $\mathrm{nd}$ \\
$\mathbf{4 g}$ & $18.0 ; 0.160 ;^{\mathrm{a}} 1.08 ;^{\mathrm{b}} 2.55^{\mathrm{c}}$ & $\mathrm{nd}$ & $\mathrm{nd}$ \\
$\mathbf{4 h}$ & 3.62 & $\mathrm{nd}$ & $\mathrm{nd}$ \\
$\mathbf{4 i}$ & 2.46 & 8.34 & $\mathrm{nd}$ \\
$\mathbf{4 j}$ & 1.69 & $\mathrm{nd}$ & $\mathrm{nd}$ \\
$\mathbf{4 k}$ & 265 & 1.27 & $\mathrm{nd}$ \\
\hline
\end{tabular}

Not determined, nd.

a Reaction temperature: $37^{\circ} \mathrm{C}$.

b Reaction temperature: $45^{\circ} \mathrm{C}$.

c Reaction temperature: $50^{\circ} \mathrm{C}$.

calculated and experimentally determined first-order rate constants suggests that the degradation pathway presented in Scheme 2 and Eq. 4 adequately describes the degradation kinetics of compounds 4 . The kinetically determined $\mathrm{p} K_{\mathrm{a}}$ values are ca. 4 units lower than those of amino acid amides ( $\mathrm{p} K_{\mathrm{a}}$ ca. 7.5-8.0). A similar observation has been reported for imidazolidin-4-ones derived from peptides ${ }^{6}$ and other compounds containing an $\alpha$-aminoamide moiety (e.g., prilocaine). ${ }^{10}$

\subsection{Reactivity and mechanism of hydrolysis}

A possible explanation for the unexpected chemical stability of compounds $\mathbf{4}$ at physiological $\mathrm{pH}$, when compared with their peptide counterparts, may be found in their mechanism of hydrolysis. According to Bundgaard and Rasmussen, imidazolidin-4-ones hydrolyze at physiological $\mathrm{pH}$, where the $k_{\text {neut }}$ pathway is dominant, via an $\mathrm{S}_{\mathrm{N}} 1$-type mechanism that involves $\mathrm{C} 2-\mathrm{N} 3$ bond cleavage and departure of an amide anion leaving group (Scheme 3 ). ${ }^{6}$ Thus, the observed differences in chemical stability may be ascribed to differences in the amide anion nucleofugacity. Indeed, amides resulting from the rate-limiting ring opening of $\mathbf{4}$ are much poorer leaving groups than those from dipeptide imidazolidin-4-ones, as suggested by the estimated difference of 3.3 $\mathrm{p} K_{\mathrm{a}}$ units between the two amide types. ${ }^{22}$ Thus, how can an apparently small difference in $\mathrm{p} K_{\mathrm{a}} \mathrm{s}$ dramatically affect the reactivity? Let us assume that the $\mathrm{pH}$-independent hydrolysis of imidazolidin-4-ones has the same susceptibility to the leaving group effect as the acyclic $N$-Mannich base counterparts, which hydrolyze via the same unimolecular mechanism. ${ }^{21}$ Since the Brönsted $\beta_{\lg }$ value for this reaction is ca.
-1 (at $37^{\circ} \mathrm{C}$ ), and assuming that the equation $\log k=$ $-\mathrm{p} K_{\mathrm{a}}+\mathrm{C}$ holds for compounds 4 , then $\log \left(k_{1} / k_{2}\right)=$ $\mathrm{p} K_{\mathrm{a}}^{2}-\mathrm{p} K_{\mathrm{a}}^{1}$ and it would be expected that compounds 4 hydrolyze ca. $10^{3}$ times slower than their counterparts derived from dipeptides. The smaller differences reported previously at $37^{\circ} \mathrm{C}$ might be attributed to the fact that the amino acid chain affects both the amide anion leaving group ability as well as the ability of the imidazolidin-4-one N-1 amino nitrogen atom to expel the amide. Further support for the unimolecular mechanism of hydrolysis of neutral imidazolidin-4-ones comes from the temperature dependence of $k_{\text {neut }}$ for $\mathbf{4 g}$ (Table 2), which yielded an entropy of activation, $\Delta S^{\#}$, value of $25 \mathrm{~J} \mathrm{~K}^{-1} \mathrm{~mol}^{-1}$. Positive $\Delta S^{\#}$ values are consistent with unimolecular mechanisms. ${ }^{23}$

Despite the limited data for the $\mathrm{pH}$-independent hydrolysis of the protonated form of imidazolidin-4-ones 4 , it is interesting to observe that $k_{\text {prot }}$ values range from $1.3 \times 10^{-2}$ to $1.5 \times 10^{-1} \mathrm{~h}^{-1}$ at $60{ }^{\circ} \mathrm{C}$ (Table 2). In contrast, imidazolidin-4-ones derived from peptides present $k_{\text {prot }}$ values ranging from $8.4 \times 10^{-3}$ to $6.6 \times 10^{-2} \mathrm{~h}^{-1}$ at $37^{\circ} \mathrm{C}$. ${ }^{4-8,10}$ Thus, the protonated form of primaquine derivatives $\mathbf{4}$ is also significantly less reactive than the corresponding ionized form of imidazolidin-4-ones derived from peptides. These results are not consistent with a mechanism of decomposition involving the rate-determining $\mathrm{C} 2-\mathrm{N} 1$ bond cleavage of the imidazolidin-4-one with departure of protonated amine leaving group, i.e., 7. If this were the case, then dipeptide imidazolidin-4-ones would be predicted to be less reactive than 4 at low $\mathrm{pH}$ as a result of electron-withdrawing effect of the $\mathrm{C}$ terminal carboxyl group $\left(7, \mathrm{R}=\mathrm{CO}_{2} \mathrm{H}\right)$ on $\mathrm{N}-1$ nitrogen atom nucleophilicity. An alternative mechanism might involve the less favorable protonation of the carbonyl oxygen atom (the $\mathrm{p} K_{\mathrm{a}}$ for the $O$-protonated amides is ca. -1$)^{24}$, followed by the $\mathrm{C} 2-\mathrm{N} 3$ bond scission, e.g., 8 , as suggested for the hydrolysis of acyclic $N$-Mannich bases in the acidic region of $\mathrm{pH}^{25}$

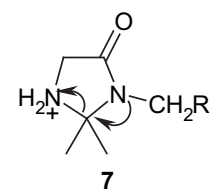

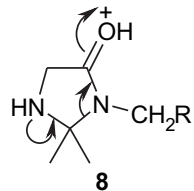

8

\subsection{Structure and energetics}

Theoretical calculations involving two models have been used to simulate the imidazolidin-4-one ring of $\mathbf{4}$, both reducing the parent primaquine (5) building block to a single methyl group, c.f. $\mathrm{R}_{4}$ in Scheme 3; the first and smaller model has substituents $\mathrm{R}_{1}=\mathrm{R}_{2}=\mathrm{R}_{3}=\mathrm{H}$ and $\mathrm{R}_{4}=\mathrm{CH}_{3}$, the

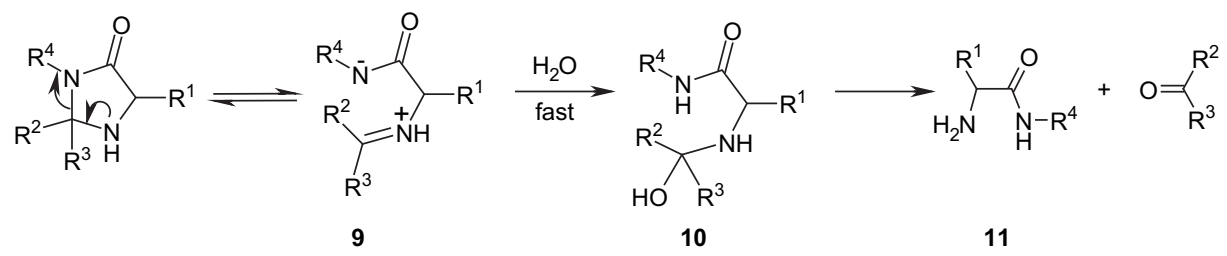



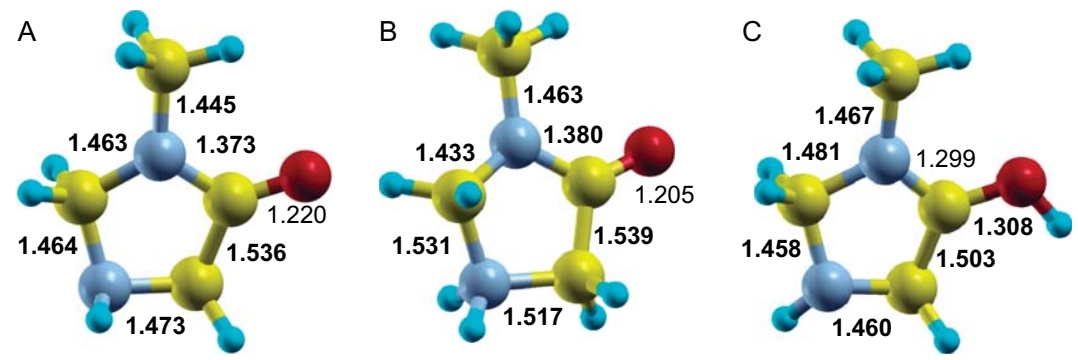

Figure 3. Optimized structures for the neutral (A), $N$-protonated (B), and $O$-protonated (C) species of the M1 model.

second resembles the imidazolidin-4-one ring of compound 4b, i.e., with $\mathrm{R}_{1}=\mathrm{CH}_{2} \mathrm{Ph}$ and $\mathrm{R}_{2}=\mathrm{R}_{3}=\mathrm{R}_{4}=\mathrm{CH}_{3}$. These two models are termed as $\mathbf{M} 1$ and $\mathbf{M} 2$ from now on. Selected geometrical data for the neutral, $\mathrm{N}$-protonated, and $O$-protonated M1 compounds are shown in Figure 3, while for M2 compounds these parameters are given as Supplementary data.

The calculations performed on these models support the hypothesis of alternative protonation sites, since the B3LYP/ 6-31G* computed enthalpic difference between the most stable $N$-protonated species and the $O$-protonated species is only 7.0 and $31.0 \mathrm{~kJ} \mathrm{~mol}^{-1}$ for M1 and $\mathbf{M} 2$ models, respectively. These values are equal to the differences between the gas-phase acidities of the $N$-protonated and $O$-protonated compounds.

Much more interesting information is retrieved from AM1 and DFT calculations on the reaction of ring opening for the neutral, $N$-protonated, and $O$-protonated M1 and M2 species. The energetic barriers for the opening of the imidazolidin-4-one ring of the neutral M1 species are depicted in Figure 4. These barriers are consistent with a unimolecular pathway for the hydrolysis of neutral $\mathbf{4}$, since the energetic barrier for the alternative pathway involving participation of a water molecule is significantly higher than that computed without water. For the neutral M2 species, AM1 and B3LYP energetic barriers are 172 and $186 \mathrm{~kJ} \mathrm{~mol}^{-1}$, respectively. The transition state structures have only one imaginary AM1 or B3LYP calculated frequency with values 196 or $81 \mathrm{~cm}^{-1}$, respectively. Again, as found for the neutral M1 species, the AM1 energetic barrier is in good agreement with that computed at the B3LYP/6-31G* level of theory.

The computed energetic barriers are much lower for the $\mathrm{N}$ protonated and $O$-protonated species as reported in Table 3. For the M1 model, the B3LYP/6-31G* computed barrier for the ring opening in the $N$-protonated species is $74 \mathrm{~kJ} \mathrm{~mol}^{-1}$, while for the $O$-protonated species, a smaller barrier is found, c.f., $64 \mathrm{~kJ} \mathrm{~mol}^{-1}$. The order of the energetic barriers

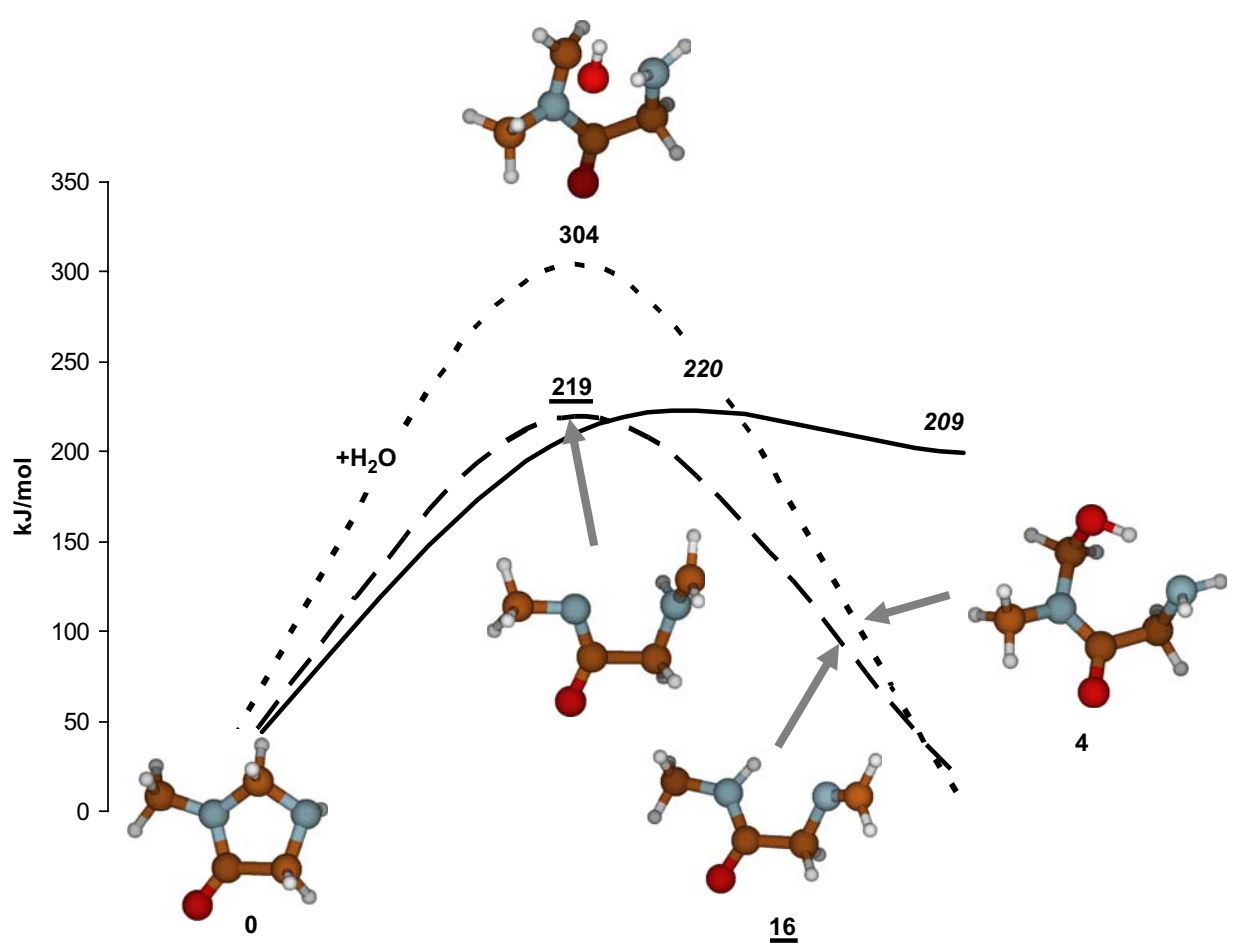

Figure 4. Energy profile for the imidazolidinone ring opening reaction, with and without a water molecule, computed at the AM1 and B3LYP/6-31G* levels of theory. The zero of energy corresponds to the reactant with or without a water molecule. Full line: AM1 in the absence of water and numbers in italic; dashed line: B3LYP in the absence of water with numbers underlined; dotted line: B3LYP in the presence of one water molecule with numbers in normal text. 
Table 3. Computed free energy differences $\left(\mathrm{kJ} \mathrm{mol}^{-1}\right)$ of TS and final product with respect to the initial (free energy $=0$ ) neutral, $N$-protonated, and $O$-protonated M1 and M2 imidazolidinone models, imaginary frequencies $\left(\mathrm{cm}^{-1}\right)$ of the TS are also given

\begin{tabular}{|c|c|c|c|c|c|c|}
\hline \multirow[t]{2}{*}{ Compound } & \multicolumn{3}{|c|}{ AM1 } & \multicolumn{3}{|c|}{ B3LYP } \\
\hline & $\mathrm{TS}$ & Product & Frequency & $\mathrm{TS}$ & Product & Frequency \\
\hline M1 neutral $+\mathrm{H}_{2} \mathrm{O}$ & 一 & - & - & 304 & 4 & -629 \\
\hline M1 neutral & 220 & 209 & -247 & 219 & 16 & -164 \\
\hline M1 $N$-protonated & 58 & -7 & -469 & 74 & 64 & -186 \\
\hline M1 $O$-protonated & 80 & 2 & -465 & 64 & 33 & -117 \\
\hline M2 neutral & 172 & 151 & -196 & 186 & 4 & -81 \\
\hline M2 $N$-protonated & 32 & -30 & -387 & 79 & 60 & -85 \\
\hline M2 $O$-protonated & 42 & -77 & -419 & - & 一 & - \\
\hline
\end{tabular}

is reversed using the AM1 approach, being $58 \mathrm{~kJ} \mathrm{~mol}^{-1}$ for the $N$-protonated species and $80 \mathrm{~kJ} \mathrm{~mol}^{-1}$ for the $O$-protonated species. Nevertheless, the small difference between the energetic barriers of these species gives further support to the possibility of a reaction mechanism involving an $O$-protonated species, as suggested previously. ${ }^{25}$ Finally, for the M2 model AM1 calculations reveal the energetic barriers to be 32 and $42 \mathrm{~kJ} \mathrm{~mol}^{-1}$ for the $N$-protonated and $O$-protonated compounds, respectively, suggesting that the reaction is faster in the case of the model resembling compound $\mathbf{4 b}$.

At first glance, the differences between the computed energy barriers for either the neutral or the protonated forms of substrate indicate that protonated imidazolidinones would be markedly less stable than their neutral forms. However, ring opening of the neutral form leads to charge separation in the gas-phase, i.e., to the formation of a highly disfavored zwitterionic species in the gaseous state. Solvation effects in aqueous media probably allow this species to be much more stabilized, thus energetically closer to the cationic species formed from the protonated substrate, which explains our experimental observation of $k_{\text {neut }}$ and $k_{\text {prot }}$ of similar magnitude for imidazolidin-4-ones $\mathbf{4 b , c , e . ~}$

\subsection{Structural effects on chemical reactivity}

Inspection of the kinetic data presented in Table 2 reveals that the $\mathrm{pH}$-independent pathway rate constant predominant at physiological $\mathrm{pH}, k_{\text {neut }}$, decreases with the increasing size of the amino acid substituent $\mathrm{R}^{1}$. This effect is more evident for the cyclopentanone, $\mathbf{4 d}-\mathbf{f}$, and cyclohexanone, $\mathbf{4 g}-\mathbf{j}$, derived series than for the corresponding acetone derived series, $\mathbf{4 a - c}$. Indeed a good correlation was obtained between $\log k_{\text {neut }}$ for the cyclohexanone, $\mathbf{4 g}-\mathbf{j}$, series and Charton's steric parameter, $\nu$, for the amino acid substituent $\mathrm{R}^{1}$ (Fig. 5). A good correlation, with a slope of -1.2 , was also determined for the three cyclopentanone derivatives $\mathbf{4 d - f}$. The negative sign of the steric term in the correlations indicates that steric crowding of the amino acid substituent retards the hydrolysis reaction of the neutral substrate. Although this may seem unusual for an $\mathrm{S}_{\mathrm{N}}$ 1-type reaction, for which release of steric strain on going from reactant to the transition state usually leads to rate enhancement, it might be ascribed to unfavorable steric interactions between the amino acid substituent and the $\mathrm{R}^{2}$ and $\mathrm{R}^{3}$ substituents in the iminium ion 9 (Scheme 3). Interestingly, when we analyzed the published data on dipeptide imidazolidin-4-ones

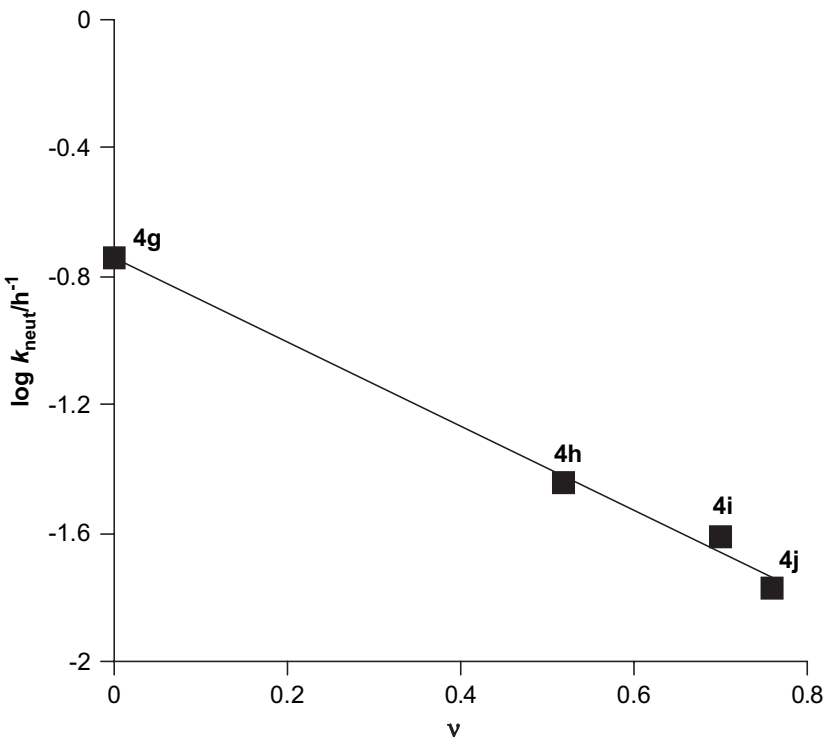

Figure 5. Plot of $\log k_{\text {neut }}$ versus Charton's steric parameter, $\nu$, for the $\mathrm{R}^{1}$ substituent in imidazolidin-4-ones $\mathbf{4 g}-\mathbf{j}$; the correlation equation for the line is: $\log k_{\text {neut }}=-1.30 \nu-0.75 \quad\left(r^{2}=0.993 ; n=4\right)$.

(1; $\mathrm{R}^{2}=\mathrm{R}^{3}=\mathrm{Me} ; \mathrm{R}^{1}=\mathrm{H}, \mathrm{Me}, \mathrm{CH}_{2} \mathrm{Ph} ; \mathrm{R}^{4}=$ phenylalanine; data determined at $37^{\circ} \mathrm{C}^{6}$ ), we found a reasonable correlation between $\log k_{\text {neut }}$ and Charton's steric parameter, $\nu$, for the amino acid substituent:

$\log k_{\text {neut }}=-0.74 \nu-2.27 \quad\left(r^{2}=0.958 ; n=3\right)$

The rate data presented in Table 2 show that the nature of the substituents at C-2 of the imidazolidin-4-one moiety, and thus the ketone starting material, affects the reactivity of the neutral form of the imidazolidin-4-ones 4. Interestingly, the order of reactivity for the glycine derivatives, according to the ketone starting material, is: cycloheptanone $>$ cyclopentanone $>$ cyclohexanone $>$ acetone, the cycloheptanone compound $\mathbf{4 k}$ being ca. 150 times more reactive than its acetone counterpart, 4a. A similar trend has been reported for imidazolidin-4-ones derived from enkephalins, where the order of reactivity is cyclopentanone $>$ cyclohexanone $>$ acetone. ${ }^{7}$

The higher reactivity of the seven- and five-membered ring derivatives, $\mathbf{4 d}, \mathbf{k}$, when compared with the six-membered ring derivative $\mathbf{4 g}$, finds parallel in the solvolysis of cycloalkyl halides and sulfonates and can be explained by Brown's I-strain (internal strain) effect. ${ }^{26-28}$ Accordingly, seven- and five-membered rings are strained, and reactions involving a change in coordination number of one of the carbon atoms from four to three, as in $\mathrm{S}_{\mathrm{N}}$ 1-type reactions, will lead to a decrease in internal strain. In contrast, six-membered halides and sulfonates are perfectly staggered and strain-free, and changes in coordination number from four to three will lead to an increase in internal strain and to a decrease in reactivity. Thus, the smaller $k_{\text {neut }}$ value for the cyclohexanone derivative $\mathbf{4 g}$, when compared with the fiveand seven-membered ring derivatives $\mathbf{4 d}, \mathbf{k}$, is also consistent with an $\mathrm{S}_{\mathrm{N}} 1$-type unimolecular mechanism. The reactivity of the acetone imidazolidin-4-one $\mathbf{4 a}$ can be ascribed to the lower stability of the corresponding ion $\mathbf{9}$ when compared 
to those derived from cyclic ketones. It has been reported that the isopropyl cation is ca. $30-40 \mathrm{kcal} \mathrm{mol}^{-1}$ less stable than methylcyclopentyl or methylcyclohexyl cation. ${ }^{29}$

Most of the $k_{\text {neut }}$ and $k_{\text {prot }}$ values for imidazolidin-4-ones 4 are of the same order of magnitude, with rate differences less than two-fold for $\mathbf{4 b , c , e}$ (Table 2). In contrast, the protonated form of the cycloheptanone derivative $\mathbf{4 k}$ is ca. 200 times less reactive than the corresponding neutral form. Interestingly, the order of reactivity for the phenylalanine derivatives, according to the ketone starting material, is: cyclohexanone $>$ cyclopentanone $>$ acetone, the cyclohexanone compound $\mathbf{4 i}$ being ca. 3 times more reactive than its acetone counterpart, $\mathbf{4 b}$. Although a similar order of reactivity has been reported for imidazolidin-4-ones derived from enkephalins, ${ }^{7}$ we cannot find an obvious explanation for these observations.

\section{Implications in prodrug design}

Imidazolidin-4-ones have been considered as useful chemically activated prodrugs for di- and larger peptides because of their reasonably rapid hydrolysis to the parent peptides in physiological conditions, i.e., pH 7.4 at $37^{\circ} \mathrm{C}$. Since the mechanism of hydrolysis of imidazolidin-4-ones is likely to involve the $\mathrm{S}_{\mathrm{N}} 1$-type unimolecular cleavage of the $\mathrm{C2}-$ N3 bond with departure of an amide-leaving group, the rate of hydrolysis of this class of prodrugs will be highly dependent on the $\mathrm{p} K_{\mathrm{a}}$ of the amide, which, in turn, is largely dependent on the nature of the amide nitrogen atom substituent (Scheme 3, 11, $\mathrm{R}^{4}$ ). The results herein presented indicate that simple $N$-alkyl $\alpha$-aminoamide drugs (11, $\mathrm{R}^{4}=$ alkyl), in contrast to peptides, will lead to stable imidazolidin-4-ones, which may be useful as slow drug release prodrugs. Increasing the size of the substituents at the $\alpha$-carbon of the $\alpha$-aminoamide parent drug will also decrease the rate of hydrolysis of the corresponding imidazolidin-4-one prodrug. In contrast, substitution at C-2 of the imidazolidin-4-one moiety will increase the rate of hydrolysis, particularly when imidazolidin-4-one prodrugs derived from cyclopentanone and cycloheptanone. In summary, the scope of imidazolidin-4-ones as prodrugs is now expanded and can encompass $\alpha$-aminoamide drugs other than peptides.

\section{Experimental}

\subsection{General details}

$N^{\alpha}$-Protected amino acids were purchased from Bachem (Switzerland). Solvents were of p.a. quality and bought from Merck (Germany). Both thin layer chromatography (TLC) aluminum foil plates covered with silica $60 \mathrm{~F}_{254}$ $(0.25 \mathrm{~mm})$ and silica gel 60 (70-230 mesh ASTM) for preparative column chromatography were also purchased from Merck. When required, solvents were previously dried with pre-activated molecular sieves $(4 \AA)$ (Merck). Other chemicals were obtained from Sigma-Aldrich.

NMR spectra were recorded on a Brüker AMX-300 spectrometer in deuterated chloroform $\left(\mathrm{CDCl}_{3}\right)$ containing tetramethylsilane (TMS) as an internal reference. Mass spectrometry (MS) was performed by the matrix-assisted laser desorption ionization-time-of-flight (MALDI-TOF) technique on an Applied Biosystems Voyager STR-DE spectrometer, using either anthracene or 2,5-dihydroxybenzoic acid (DHB) as adjuvant matrices.

\subsection{Synthesis of imidazolidin-4-ones 4}

The aminoacyl derivatives of primaquine 6 ( $2 \mathrm{mmol})$ were mixed with an excess $(4 \mathrm{mmol})$ of the appropriate ketone (acetone, cyclopentanone, cyclohexanone, or cycloheptanone) and triethylamine (TEA, $2 \mathrm{mmol}$ ) in dry methanol $(10 \mathrm{ml})$ and the mixture was refluxed for 3 days in the presence of $4 \AA$ molecular sieves ( $1 \mathrm{~g}$ ). The reaction was monitored by TLC and ketone was re-added $(2 \mathrm{mmol})$ once per day. The molecular sieves were removed by decantation and the solution was evaporated to dryness. The oily residue was submitted to column chromatography on silica gel, eluted with DCM/THF (varying solvent proportions) or, for compound 4a, DCM/ethanol 15:1 (v/v). Fractions containing the chromatographically homogeneous product were pooled and evaporated to dryness, yielding $4 \mathbf{a}-\mathbf{k}$ as yellow-orange oils (44 to $81 \%$ ) that were analyzed by high-resolution MS and NMR. Spectroscopic and analytical data for compounds $\mathbf{4 a}-\mathbf{k}$ have been presented in Ref. 11 .

\subsection{Kinetics of hydrolysis}

The kinetics of hydrolysis of imidazolidin-4-ones 4 were studied by HPLC using a Waters ${ }^{\circledR}$ assembly equipped with a model 600 controlled pump and a model 991 photodiodearray detector set at $265 \mathrm{~nm}$. The separation was performed on a Purospher ${ }^{\circledR}, 250 \times 4.0-\mathrm{mm}$ i.d. $5 \mu \mathrm{m}$ analytical column. The mobile phase consisted of a mixture of acetonitrile and sodium acetate buffer ( $\mathrm{pH} 4.75,0.05 \mathrm{M}$ ) containing $10^{-3} \mathrm{M}$ triethylamine. Two gradients were developed: one for the imidazolidin-4-one derivatives of phenylalanine and the other for the derivatives of valine. A linear gradient method using 50-90\% (v/v) acetonitrile over 20 min was used for compounds $\mathbf{4 b}, \mathbf{e}, \mathbf{i}$, while a linear gradient using 60-90\% (v/v) acetonitrile over $20 \mathrm{~min}$ was used for compounds $\mathbf{4 c , f , j}$. For the remaining compounds, an isocratic method was developed using a mixture of acetonitrile and $\mathrm{pH} 4.75$ acetate buffer (50:50 to 60:40\%) containing $10^{-3} \mathrm{M}$ triethylamine.

The kinetics of hydrolysis of imidazolin-4-ones 4 were studied at $60 \pm 0.1^{\circ} \mathrm{C}$, in aqueous buffers with ionic strength kept at $0.5 \mathrm{M}$ by the addition of $\mathrm{NaClO}_{4}$. The buffers used were acetate ( $\mathrm{pH} 4.0-5.0)$, phosphate $(\mathrm{pH}$ 6.0-7.5), and borate (pH 8.0-11.5). For acetate and phosphate buffers the effect of buffer concentration was studied in the range 0.01$0.20 \mathrm{M}$. Sodium hydroxide and hydrochloric acid pseudobuffers were used at $\mathrm{pH}$ higher than 12.0 and lower than 2.5 , respectively. Typically, reactions were initiated by injecting a $10 \mu \mathrm{l}$ aliquot of a $10^{-2} \mathrm{M}$ stock solution of substrate in acetonitrile to $10 \mathrm{ml}$ of the appropriate thermostated buffer solution. At regular intervals, samples of the reaction mixture were analyzed by HPLC. All reactions followed first-order kinetics over four half lives. Rate constants derived using this method were reproducible to $\pm 6 \%$. 


\subsection{Computational details}

The semiempirical Austin Model 1, AM1 ${ }^{30}$ and the densityfunctional theory, DFT, based B3LYP ${ }^{31-33}$ methods have been used as included in the Gaussian 98 computer code. ${ }^{34}$ These two methods have been parameterized in order to reproduce experimentally measured molecular properties. The simplest AM1 method is based on the neglect of differential diatomic overlap formalism in which various Fock matrix elements are set to zero or use parameters optimized to reproduce various properties such as molecular geometries and standard gas-phase enthalpies of formation. This approach is an evolution of the older Modified Neglect of Differential Overlap, MNDO, method where some deficiencies, such as poor reproduction of hydrogen bonds and too high reaction activation energies, have been corrected. In the hybrid B3LYP method, three parameters of the exchange functional were optimized empirically in order to reproduce experimental thermochemical data. The optimum mixing was found for $20 \%$ Fock exchange in the exchange functional. In the B3LYP calculations reported here, the atomic electronic density has been described by the standard 6-31G(d) basis set.

Transition states were localized using the STQN method, QST3 and IRC calculations were performed in order to be certain that these TS structures yield the closed-ring (reactants) and open-ring (products) structures. Further, reactants and products did not present any imaginary frequency while only a single imaginary frequency was calculated for transition states. All figures with molecular structures have been obtained with the XCrysDen ${ }^{35}$ and Molden ${ }^{36}$ programs.

\section{Acknowledgements}

The authors thank Fundação para a Ciência e Tecnologia (Portugal) for financial support through research project POCTI/FCB/39218/2001 and pluriannual funding to research units CECF and CIQUP. J.R.B.G. and P.C. thank F.C.T. and the European Social Fund (ESF) under the 3rd Community Support Framework (CSF) for the award, respectively, of a post-doctoral fellowship (SFRH/BPD/ 11582/2002) and a Ph.D. research grant (SFRH/BD/11582/ 2002).

\section{Supplementary data}

Table S1 with the optimized Cartesian coordinates and Table S2 with the energies of all compounds. Supplementary data associated with this article can be found in the online version, at doi:10.1016/j.tet.2006.08.026.

\section{References and notes}

1. Zehavi, U.; Ben-Ishai, D. J. Org. Chem. 1961, 26, 1097-1101.

2. Panetta, C. A.; Pesh-Imam, M. J. Org. Chem. 1972, 37, 302304.

3. Hardy, P. M.; Samworth, D. J. J. Chem. Soc., Perkin Trans. 1 1977, 1954-1960.

4. Klixbull, U.; Bundgaard, H. Int. J. Pharm. 1985, 23, 163-173.
5. Klixbull, U.; Bundgaard, H. Int. J. Pharm. 1984, 20, 273-284.

6. Rasmussen, G. J.; Bundgaard, H. Int. J. Pharm. 1991, 71, $45-53$.

7. Rasmussen, G. J.; Bundgaard, H. Int. J. Pharm. 1991, 76, 113-122.

8. Bak, A.; Fich, M.; Larsen, B. D.; Frokjaer, S.; Friis, G. J. Eur. J. Pharm. Sci. 1999, 7, 317-323.

9. Jusko, W. J.; Lewis, G. P. J. Pharm. Sci. 1973, 62, 69-76.

10. Larsen, S. W.; Sidenius, M.; Ankersen, M.; Larsen, C. Eur. J. Pharm. Sci. 2003, 20, 233-240.

11. Gomes, P.; Araújo, M. J.; Rodrigues, M.; Vale, N.; Azevedo, Z.; Iley, J.; Chambel, P.; Morais, J.; Moreira, R. Tetrahedron 2004, 60, 5551-5562.

12. Araújo, M. J.; Bom, J.; Capela, R.; Casimiro, C.; Chambel, P.; Gomes, P.; Iley, J.; Lopes, F.; Morais, J.; Moreira, R.; de Oliveira, E.; do Rosário, V.; Vale, N. J. Med. Chem. 2005, 48, 888-897.

13. Baker, J. K.; Bedford, J. A.; Clark, A. M.; McChesney, J. D. Pharm. Res. 1984, 1, 98-100.

14. Mihaly, G. W.; Ward, S. A.; Edwards, G.; Orme, M. L'E.; Breckenridge, A. M. Br. J. Clin. Pharmacol. 1984, 17, 441446.

15. Brossi, A.; Millet, P.; Landau, I.; Bembenek, M. E.; Abell, C. W. FEBS Lett. 1987, 214, 291-294.

16. Constantino, L.; Paixão, P.; Moreira, R.; Portela, M. J.; Rosário, V. E.; Iley, J. Exp. Toxicol. Pathol. 1999, 51, 299-303.

17. Brueckner, R. P.; Ohrt, C.; Baird, J. K.; Milhous, W. K. 8Aminoquinolines. In Antimalarial Chemotherapy; Rosenthal, P. J., Ed.; Humana: Totowa, NJ, 2001; pp 123-151.

18. Laidler, K. Chemical Kinetics; Tata McGraw-Hill: New Delhi, 1978; pp 321.

19. Jencks, W. P.; Regenstein, J. Ionization Constants of Acids and Bases. In Handbook of Chemistry and Molecular Biology, 3rd ed.; Fasman, G. D., Ed.; CRC: Cleveland, OH, 1976; Vol. 1, p 305.

20. Perrin, D. D.; Dempsey, B.; Serjeant, E. P. $p K_{a}$ Prediction for Organic Acids and Bases; Chapman and Hall: London, 1981; pp 109.

21. Bundgaard, H.; Johansen, M. Arch. Pharm. Chem. Sci. Ed. 1980, 8, 29-52.

22. The $\mathrm{p} K_{\mathrm{a}}$ values for the dissociation of amides $\mathrm{R}^{1} \mathrm{CONHR}{ }^{2}$ can be calculated using the equation $\mathrm{p} K_{\mathrm{a}}=22-3.1 \sum \sigma^{*}$ (Ref. 20). The difference between the amide derived from primaquine and those from peptides is in the $\mathrm{R}^{2}$ group. For simplicity, we considered the $\mathrm{R}^{2}$ group for primaquine to be butyl $\left(\sigma^{*}-0.23\right)$ and for the peptides to be $\mathrm{MeNHCOCH}_{2}$ (for which $\sigma^{*}$ can be estimated to be 0.84$)$; thus, the difference in $\mathrm{p} K_{\mathrm{a}}$ is $3.1(0.84-(-0.23)) \approx 3.3$.

23. Lopes, F.; Moreira, R.; Iley, J. J. Chem. Soc., Perkin Trans. 2 1999, 431-440.

24. Homer, R. B.; Johnson, C. D. Acid-Base and Complexing Properties of Amides. In The Chemistry of Amides; Zabicky, J., Ed.; Interscience: London, 1970; p 187.

25. Loudon, G. M.; Almond, M. R.; Jacob, J. N. J. Am. Chem. Soc. 1981, 103, 4508-4515.

26. Brown, H. C.; Fletcher, R. S.; Johannesen, R. B. J. Am. Chem. Soc. 1951, 73, 212-221.

27. Brown, H. C.; Ham, G. J. Am. Chem. Soc. 1956, 78, 27352739.

28. Masson, E.; Leroux, F. Helv. Chim. Acta 2005, 88, 1375-1386.

29. Wolf, J. F.; Staley, R. H.; Koppel, I.; Taagepera, M.; McIver, R. T., Jr.; Beauchamp, J. L.; Taft, R. W. J. Am. Chem. Soc. 1977, 99, 5417-5429. 
30. Dewar, M. J. S.; Zoebisch, E. G.; Healy, E. F.; Stewart, J. J. P. J. Am. Chem. Soc. 1985, 107, 3902-3909.

31. Becke, A. D. Phys. Rev. A 1988, 38, 3098-3100.

32. Becke, A. D. J. Chem. Phys. 1993, 98, 5648-5652.

33. Lee, C.; Yang, W.; Parr, R. G. Phys. Rev. B 1980, 37, 785-789.

34. Frisch, M. J.; Trucks, G. W.; Schlegel, H. B.; Scuseria, G. E.; Robb, M. A.; Cheeseman, J. R.; Zakrzewski, V. G.; Montgomery, J. A., Jr.; Stratmann, R. E.; Burant, J. C.; Dapprich, S.; Millan, J. M.; Daniels, A. D.; Kudin, K. N.; Strain, M. C.; Farkas, O.; Tomasi, J.; Barone, V.; Cossi, M.; Cammi, R.; Mennucci, B.; Pomelli, C.; Adamo, C.; Clifford, S.; Ochterski, J.; Petersson, G. A.; Ayala, P. Y.; Cui, G.;
Morokuma, K.; Malick, D. K.; Rabuck, A. D.; Raghavachari, K.; Foresman, J. B.; Cioslowski, J.; Ortiz, J. V.; Stefanov, B. B.; Liu, G.; Liashenko, A.; Piskorz, P.; Komaromi, I.; Gomperts, R.; Martin, R. L.; Fox, D. J.; Keith, T.; Al-Laham, M. A.; Peng, C. Y.; Nanayakkara, A.; Gonzalez, C.; Challacombe, M.; Gill, P. M. W.; Johnson, B.; Chen, B.; Wong, M. W.; Andres, J. L.; Head-Gordon, M.; Replogle, E. S.; Pople, J. A. Gaussian 98, Revision A.9; Gaussian: Pittsburgh, PA, 2000.

35. Kokalj, A. J. Mol. Graphics Modell. 1999, 17, 176-179.

36. Schaftenaar, G.; Noordik, J. H. J. Comput.-Aided Mol. Des. 2000, 14, 123-134. 